\title{
A copula-based flexible-stochastic programming method for planning regional energy system under multiple uncertainties: A case study of the urban agglomeration of Beijing and Tianjin
}

\author{
L. $\mathrm{Yu}^{1}$, Y.P. Li ${ }^{2 *}$, G.H. Huang ${ }^{3}$, Y.R. Fan ${ }^{4}$, S. $\mathrm{Nie}^{5}$ \\ ${ }^{1}$ Research Assistant, Sino-Canada Energy and Environmental Research Center, North China Electric \\ Power University, Beijing 102206, China; E-mail: yulei1060220069@sina.com \\ $2^{2 *}$ (Corresponding Author) Professor, Environment and Energy Systems Engineering Research Center, \\ School of Environment, Beijing Normal University, Beijing 100875, China; E-mail: \\ yongping.li@iseis.org \\ ${ }^{3}$ Professor and Canada Research Chair, Institute for Energy, Environment and Sustainable Communities, \\ University of Regina, Regina, Sask. S4S 0A2, Canada; E-mail: gordon.huang@uregina.ca \\ ${ }^{4}$ Research Assistant, Institute for Energy, Environment and Sustainable Communities, University of \\ Regina, Regina, Sask. S4S 7H9, Canada; E-mail: yurui.fan@gmail.com \\ ${ }^{5}$ Research Assistant, Faculty of Applied Science and Engineering, University of Toronto, Toronto, ON \\ M5S 1A4, Canada; E-mail: nschina01@gmail.com
}




\begin{abstract}
In this study, a copula-based flexible-stochastic programming (CFSP) method is developed for planning regional energy system (RES). CFSP can deal with multiple uncertainties expressed as interval values, random variables and fuzzy sets as well as their combinations employed to objective function and soft constraints. It can also reflect uncertain interactions among random variables through using copula functions even having different probability distributions and previously unknown correlations. Then, based on the developed CFSP approach, a CFSP-RES model is formulated for planning RES of the urban agglomeration of Beijing and Tianjin (China). Results disclose that uncertainties existed in the system components have significant effects on the outputs of decision variables and system cost, and the variation of system cost is reached $16.3 \%$. Results also reveal that air pollutant emissions can be mitigated if the urban agglomeration can co-implement renewable energy development plans (REDP) over the planning horizon, with the reductive rates of $[3.3,7.6] \%$ of sulfur dioxide $\left(\mathrm{SO}_{2}\right),[2.7,4.1] \%$ of nitrogen oxides $\left(\mathrm{NO}_{\mathrm{x}}\right)$ and $[7.0,11.5] \%$ of particulate matter $\left(\mathrm{PM}_{10}\right)$. Compared to joint-probabilistic chance-constrained programming (JCP), the CFSP method is more effective for handling multiple random parameters associated with different probability distributions in which their correlations are unknown. Thus, it is not limited to some unjustified assumptions and can be applied to a wider range of problems than previous studies. The findings are helpful to explore the influence of interaction among random variables on modeling outputs and provide in-depth analysis for identifying desired decision schemes for planning RES.
\end{abstract}

Keywords: copula, interaction of random variables; multiple uncertainties; programming; pollutant mitigation, regional energy system 


\section{Introduction}

Over the past decades, the world has undergone rapid economic development and social revolution corresponding to the increasing energy demand. Global energy consumption grew at a rate of $2.3 \%$ in $2000-2015$, and is projected to slow towards $0.9 \%$ in $2035-2050$, with more than three-quarters of total energy supplies are still dependent on fossil fuels (i.e. coal, gas and oil) [1]. Meanwhile, the infrastructural investments and pollutant emissions associated with power industry have adverse impacts on environment. For example, according to the International Energy Agency (IEA), around 6.5 million deaths are attributed each year to poor air quality, making this the world's fourth-largest threat to human health, behind high blood pressure, dietary risks and smoking [2]. Air pollution is a major public health crisis, with many of its root causes and cures to be found in the energy sector. Therefore, how to effectively balance the contradiction between energy demand-supply reliability and air quality improvement continues to be great challenges faced by decision makers [3].

Previously, numerous inexact optimization approaches such as Monte Carlo simulation (MCS), chance-constrained programming (CCP), two-stage stochastic programming (TSP) and multistage stochastic programming (MSP) were proposed for dealing with stochastic problems with known probability distributions in the energy system [4-9]. For example, Hemmati et al. [4] used a MCS-based stochastic planning method for congestion management in electric power systems, in which uncertainties of wind and solar resources were handled. Odetayo et al. [6] proposed a CCP approach to integrated planning of distributed power generation and natural gas network in the presence of uncertain real and reactive power demand. Simic [9] developed a multistage interval-stochastic programming model for planning end-of-life vehicles allocation, where uncertainties expressed as probability distributions and discrete intervals were effectively tackled based on a multi-layered scenario tree with a finite set of scenarios. Summarily, these inexact optimization methods are based on MCS and CCP for handling random variables with known probability distributions in the right-hand sides of the constraints, TSP for tackling problems where an analysis of policy scenarios is desired and the right-hand-side coefficients are random with known probability distributions, MSP for permitting revised decisions in each time stage based on the sequentially realized uncertain events; while few of them are employed to 
analyze interactive relationships among multiple random parameters in the energy system [10, 11]. Besides, the conventional joint-probabilistic chance-constrained programming (JCP) methods for reflecting interactive relationships among a set of probabilistic constraints are based on assumptions that all of random variables employed to probabilistic constraints are normally and independently distributed $[12,13]$. However, in most of real-world regional energy system (RES) planning problems, different random variables may present different probability distributions and the associated correlation may be previously unknown [14]. Thus, the existing JCP methods may encounter difficulty in application to the cases where the random parameters follow different probability distributions and have previously unknown correlations.

Copula-based stochastic programming (CSP) method has advantages of handling JCP problems having different probability distributions and unknown relationship of random variables in the right-hand sides of constraints $[15,16]$. However, a review of the literature shows no reports on reflecting interactions among multiple random parameters (e.g., electricity demands of different urban cities in the urban agglomeration) having previously unknown probability distributions and unknown correlations in the RES planning models. Additionally, in real-world RES planning problems, some system parameters are not available as deterministic values but can present as discrete intervals or fuzzy sets owing to the incompleteness or impreciseness of observed information [17-19]. Flexible programming (FP) is effective for supporting different kinds of fuzzy numbers as well as various fuzzy ranking methods in soft constraints to defuzzify uncertain parameters [20, 21]. Interval-parameter programming (IPP) can deal with uncertainties expressed as interval numbers without distributional information [22, 23].

Therefore, the objective of this study devotes to exploiting a copula-based flexible-stochastic programming (CFSP) method for planning the RES management problems. CFSP will be formulated through integrating CSP, FP and IPP within a general mixed-integer linear programming (MILP) framework. Then, based on the developed CFSP approach, a CFSP-RES model is formulated for planning RES of the urban agglomeration of Beijing and Tianjin (China). In the CFSP-RES model, fifteen scenarios under different joint constraint-violation levels and various individual constraint-violation levels are selected to verify the interaction of electricity demands between the urban cities of Beijing and Tianjin. Four satisfaction degrees of flexible 
constraints on fixed and variable costs are used for dealing with soft constraints and flexibilities on target value of goals. Results will help decision makers: (a) deal with multiple uncertainties existed in the RES; (b) identify optimal energy-supply patterns; (c) reach tradeoffs among energy-supply reliability, system cost and environment mitigation; (d) reflect interactions among random variables and disclose their impacts on modeling outputs.

\section{Methodology}

\subsection{Copula-based stochastic programming}

The "copula" approach for modeling multivariate joint distributions was proposed by Sklar in 1959 [24]. This approach shows that a multivariate joint distribution can be completely characterized by its respective marginal distributions and a copula function for binding them together independent of the types of individual marginal distributions [15]. Modeling joint distributions using copulas has effectiveness in allowing researchers to take into account marginal distributions and dependence as two separate but related issues [25-29]. Based on Nelsen [24], Charnes et al. [30] and Infanger and Morton [31], a copula-based stochastic programming (CSP) model can be formulated as follows:

$$
\operatorname{Min} E=\sum_{j=1}^{n} c_{j} x_{j}
$$

subject to:

$$
\begin{aligned}
& \operatorname{Pr}\left\{\sum_{j=1}^{n} a_{i j} x_{j} \leq b_{i}^{r v}, i=1,2, \ldots, k\right\} \geq 1-p \\
& \sum_{j=1}^{n} a_{i j} x_{j} \leq b_{i}, i=k+1, k+2, \ldots, m \\
& x_{j} \geq 0, j=1,2, \ldots, n
\end{aligned}
$$

where $x_{j}$ are decision variables; $E$ is a linear objective function; $a_{i j}$ and $b_{i}$ are constraints' coefficients; $b_{i}^{r v}(i=1,2, \ldots, k)$ are random variables with unknown probability distribution; $1-p$ is a prescribed joint probability level at which the entire set of chance constraints are 
enforced to be satisfied.

Based on Chen et al. [15], the joint chance constraints of (1b) can be converted into the corresponding individual chance constraints as follows:

$$
\begin{aligned}
& \operatorname{Pr}\left\{\sum_{j=1}^{n} a_{i j} x_{j} \leq b_{i}^{r v}\right\} \geq 1-p_{i}, i=1,2, \ldots, k \\
& C\left(1-p_{1}, 1-p_{2}, \ldots, 1-p_{k}\right)=1-p
\end{aligned}
$$

where $C$ is the best copula determined previously; $p_{i}(i=1,2, \ldots, k)$ are probabilistic violation levels for individual chance constraints (2a), which are also known as significance levels representing the acceptable risk of constraint violation.

According to Charnes and Cooper [32], constraint (1b) can be transformed as:

$$
\sum_{j=1}^{n} a_{i j} x_{j} \leq b_{i}^{p_{i}}, i=1,2, \ldots, k
$$

Therefore, the CSP method defined in model (1) can be transformed as follows:

$$
\operatorname{Min} E=\sum_{j=1}^{n} c_{j} x_{j}
$$

subject to:

$$
\begin{aligned}
& \sum_{j=1}^{n} a_{i j} x_{j} \leq b_{i}^{p_{i}}, i=1,2, \ldots, k \\
& C\left(1-p_{1}, 1-p_{2}, \ldots, 1-p_{k}\right)=1-p \\
& \sum_{j=1}^{n} a_{i j} x_{j} \leq b_{i}, i=k+1, k+2, \ldots, m \\
& x_{j} \geq 0, j=1,2, \ldots, n
\end{aligned}
$$

where $b_{i}^{p_{i}}=F_{i}^{-1}\left(p_{i}\right)$, given the cumulative distribution function of $b_{i}\left(i . e . F_{i}\left(b_{i}\right)\right)$, and the probability of violating constraint $i$ (i.e. $\left.p_{i}\right)$. 


\subsection{Interval-flexible programming}

Flexible programming (FP) is effective for handling flexibility on target value of goals and soft constraints [33]. Based on Cadenas and Verdegay [34] and Peidro et al. [35], a FP model can be depicted as follows:

Min $E=c x+f y$

subject to:

$$
\begin{aligned}
& A x \geq d-\tilde{t}(1-\alpha) \\
& B x=0 \\
& S x \leq N y+[\tilde{r}(1-\beta)] y \\
& T y \leq 1 \\
& y \in\{0,1\}, x \geq 0
\end{aligned}
$$

where vectors $x$ and $y$ are regarded as continuous and binary variables, respectively; vectors $f$ and $c$ are related to fixed opening costs of facilities and variable activity costs, respectively; vector $d$ is representative of customers' demand; matrices $A, B, S, T$ and $N$ represent constraints' coefficients where $N$ is indicator of facilities' capacity.

Parameters $\alpha$ and $\beta$ are indicator of minimum satisfaction level of flexible constraints. Triangular fuzzy numbers $\tilde{t}$ and $\tilde{r}$ can be represented by three prominent points (i.e. $\tilde{t}=\left(t^{p}, t^{m}, t^{o}\right)$ and $\left.\tilde{r}=\left(r^{p}, r^{m}, r^{o}\right)\right)$. Based on the fuzzy ranking method suggested by [36, 37], $\tilde{t}$ and $\tilde{r}$ can be defuzzified as follows:

$$
\begin{aligned}
& \left(t^{m}+\frac{\vartheta_{t}-\vartheta_{t}^{\prime}}{3}\right) \\
& \left(r^{m}+\frac{h_{r}-h_{r}^{\prime}}{3}\right)
\end{aligned}
$$

where parameters $\vartheta_{t}$ and $\vartheta_{t}^{\prime}\left(h_{r}\right.$ and $h_{r}^{\prime}$ ) are lateral margins of the triangular fuzzy number $\tilde{t}(\tilde{r})$ and can be defined as follows: 


$$
\begin{aligned}
& \vartheta_{t}=t^{o}-t^{m} \\
& \vartheta_{t}^{\prime}=t^{m}-t^{p}
\end{aligned}
$$

The FP model has advantage of dealing with uncertain parameters in virtue of various fuzzy ranking approaches and different satisfaction degrees. However, in many practical problems, uncertainties are often existed as discrete intervals with known lower and upper bounds. IPP is capable of handling the uncertainties expressed as intervals without probability distributions and flexibility on target value of goals $[22,38]$. Through integrating IPP into FP, an interval-flexible programming (IFP) model can be formulated as follows:

$$
\operatorname{Min} E^{ \pm}=\sum_{j=1}^{k} c^{ \pm} x^{ \pm}+\sum_{j=k+1}^{n} c^{ \pm} x^{ \pm}+\sum_{j=1}^{k} f_{j}^{ \pm} y+\sum_{j=k+1}^{n} f_{j}^{ \pm} y
$$

subject to:

$$
\begin{aligned}
& \sum_{j=1}^{k} a_{i j}^{ \pm} x_{j}^{ \pm}+\sum_{j=k+1}^{n} a_{i j}^{ \pm} x_{j}^{ \pm} \geq d_{i}^{ \pm}-\left(t^{m}+\frac{\vartheta_{t}-\vartheta_{t}^{\prime}}{3}\right)(1-\alpha), i=1,2, \ldots, m \\
& B^{ \pm} x_{j}^{ \pm}=0 \\
& S^{ \pm} x_{j}^{ \pm} \leq N^{ \pm} y+\left[\left(r^{m}+\frac{h_{r}-h_{r}^{\prime}}{3}\right)(1-\beta)\right] y \\
& T^{ \pm} y \leq 1 \\
& y \in\{0,1\}, x_{j}^{ \pm} \geq 0, j=1,2, \ldots, n
\end{aligned}
$$

where $a_{i j}^{ \pm} \in\left\{R^{ \pm}\right\}^{m \times n}, \quad d_{i}^{ \pm} \in\left\{R^{ \pm}\right\}^{m \times 1}, c_{j}^{ \pm} \in\left\{R^{ \pm}\right\}^{1 \times n}, x_{j}^{ \pm} \in\left\{R^{ \pm}\right\}^{n \times 1} ; R^{ \pm}$mean a set of interval numbers; $x_{j}^{ \pm}$denote decision variables that are divided into two categories: continuous and binary variables; $c_{j}^{ \pm}(j=1,2, \ldots, k)$ and $a_{i j}^{ \pm}(j=1,2, \ldots, k)$ show positive coefficients; $c_{j}^{ \pm}(j=k+1, k+2, \ldots, n)$ and $a_{i j}^{ \pm}(j=k+1, k+2, \ldots, n)$ imply negative coefficients.

\subsection{Copula-based flexible-stochastic programming}

In decision-making problems, acquired data may subject to some errors owing to spatial and 
temporal variations, as well as the incompleteness or impreciseness of observed information. This can lead to multiple uncertainties of interactive random variables, interval values, and flexible constraints. Therefore, one effective approach for dealing with such complex uncertainties can be developed by coupling IFP into CSP. A copula-based flexible-stochastic programming (CFSP) model can then be formulated as follows:

$$
\operatorname{Min} E^{ \pm}=\sum_{j=1}^{k} c^{ \pm} x^{ \pm}+\sum_{j=k+1}^{n} c^{ \pm} x^{ \pm}+\sum_{j=1}^{k} f_{j}^{ \pm} y+\sum_{j=k+1}^{n} f_{j}^{ \pm} y
$$

subject to:

$$
\begin{aligned}
& \sum_{j=1}^{k} a_{i j}^{ \pm} x_{j}^{ \pm}+\sum_{j=k+1}^{n} a_{i j}^{ \pm} x_{j}^{ \pm} \geq\left(d_{i}^{p_{i}}\right)^{ \pm}-\left(t^{m}+\frac{\vartheta_{t}-\vartheta_{t}^{\prime}}{3}\right)(1-\alpha), i=1,2, \ldots, k \\
& C\left(1-p_{1}, 1-p_{2}, \ldots, 1-p_{k}\right)=1-p \\
& \sum_{j=1}^{k} a_{i j}^{ \pm} x_{j}^{ \pm}+\sum_{j=k+1}^{n} a_{i j}^{ \pm} x_{j}^{ \pm} \geq d_{i}^{ \pm}, i=k+1, k+2, \ldots, m \\
& B^{ \pm} x_{j}^{ \pm}=0 \\
& S^{ \pm} x_{j}^{ \pm} \leq N^{ \pm} y+\left[\left(r^{m}+\frac{h_{r}-h_{r}^{\prime}}{3}\right)(1-\beta)\right] y \\
& T^{ \pm} y \leq 1 \\
& y \in\{0,1\}, x^{ \pm} \geq 0, j=1,2, \ldots, n
\end{aligned}
$$

The detailed solution algorithm for solving the CFSP method is depicted in Appendix A to this paper.

\section{Case Study}

The CFSP method is applied to planning RES of the urban agglomeration of Beijing and Tianjin that are both located in the northern part of the North China Plain (Figure 1). As two municipalities directly under the central government, Beijing and Tianjin are both confronting tremendous pressure to satisfy the increasing electricity demand corresponding to rapid population growth and economic development. For Beijing, by the year of 2015, its electricity consumption reached $95.3 \times 10^{3} \mathrm{GWh}$ while its domestic electricity production was $54.1 \times 10^{3}$ 
GWh; for Tianjin, its electricity consumption and domestic electricity production were respectively $85.1 \times 10^{3} \mathrm{GWh}$ and $64.3 \times 10^{3} \mathrm{GWh}$. For the entire RES, more than $34 \%$ of electricity was insufficient and imported from adjacent power grids. Additionally, among the domestic RES electricity-supply patterns, fossil-based power occupied more than $95 \%$ while renewable energy took a minor share. Contradictions of energy demand-supply balance and sustainable power development have aggravated significantly and been one of the major concerns of the RES planning.

Place Figure 1 here

For the RES planning of Beijing and Tianjin, eight power-conversion technologies were considered for generating electricity. The power-conversion technologies involve non-renewable energy (i.e. coal and gas) and renewable energy (i.e. wind, photovoltaic, biomass, waste, hydro and pumped-storage). Four adjacent power grids (i.e. Hebei power grid, Shaanxi power grid, Shandong power grid and Inner Mongolia power grid) were used for exporting electricity to satisfy the electricity demand of RES. Besides, renewable energy development plans (abbreviated as REDP) of Beijing and Tianjin in years of 2016-2020 were implemented to reduce dependency on fossil energies and cut air-pollutant emissions. In detail, according to the $13^{\text {th }}$ Five-year-plan (i.e. years 2016-2020) of renewable energy development, by the end of 2020, the installed capacity of renewable energy in Beijing would be reached $2.0 \mathrm{GW}$, which would account for approximately $15.0 \%$ of total installed capacity; compared to Beijing, Tianjin would expedite development of renewable energies, and the total installed capacity of wind, photovoltaic, biomass and waste power would be reached $1.16 \mathrm{GW}, 0.80 \mathrm{GW}, 0.12$ and $0.04 \mathrm{GW}$, respectively.

In addition, one of problems for RES planning faced by decision makers is the multi-uncertainty associated with various characteristic features in the study system [39, 40]. The uncertain parameters in the RES of Beijing and Tianjin can be classified into three categories: (a) uncertainties come from mathematical sense, which presents the difference between measured, estimated values and true values in observation or calculation; (b) uncertainties exist in the 
inherent variation of system, such as energy supply, conversion, transmission and utilization as well as environmental mitigation; (c) uncertainties initiate outside of the system including meteorological, socio-economic, environmental, technical and political implications [41]. For example, availabilities of renewable energy resources (e.g., hydro, wind and solar) are highly dependent on meteorological conditions that fluctuate within a certain range due to climate change. Such variations of renewable energy availabilities would then affect operating statuses of relevant power-conversion facilities (i.e. hydro power, wind power and photovoltaic power), resulting in changes in their energy outputs [42].

Based on the proposed CFSP method, a CFSP-RES model can be developed for planning the RES. The objective of CFSP-RES aims at allocating power-supply patterns and planning capacity expansions of power-conversion facilities to achieve the minimum system cost without exceeding the required pollutant discharge and the given joint constraint-violation level. The system cost includes cost of energy resource purchase, investment for power-conversion facilities and penalty for electricity-shortage as well as capital of pollutant-mitigation.

$$
\begin{aligned}
& \text { Min } E^{ \pm}=\sum_{c=1}^{2} \sum_{j=1}^{3} \sum_{t=1}^{5} P E C_{c, j, t}^{ \pm} \times N Y L_{c, j, t}^{ \pm} \\
& +\sum_{c=1}^{2} \sum_{t=1}^{5} P E J_{c, t}^{ \pm} \times P E_{c, t}^{ \pm} \\
& +\sum_{c=1}^{2} \sum_{k=1}^{8} \sum_{t=1}^{5} F G C_{c, k, t}^{ \pm} \times\left(R C_{c, k, t=0}^{ \pm}+E C_{c, k, t}^{ \pm} \times Y C_{c, k, t}\right) \\
& +\sum_{c=1}^{2} \sum_{k=1}^{8} \sum_{t=1}^{5} V G C_{c, k, t}^{ \pm} \times\left(E G A_{c, k, t}^{ \pm}+E C_{c, k, t}^{ \pm} \times Y C_{c, k, t} \times S T_{c, k, t}^{ \pm}\right) \\
& +\sum_{c=1}^{2} \sum_{k=1}^{8} \sum_{t=1}^{5}\left(F E C_{c, k, t}^{ \pm}+V E C_{c, k, t}^{ \pm}\right) \times E C_{c, k, t}^{ \pm} \times Y C_{c, k, t} \\
& +\sum_{c=1}^{2} \sum_{k=1}^{8} \sum_{t=1}^{5}\left(E G A_{c, k, t}^{ \pm}+E C_{c, k, t}^{ \pm} \times Y C_{c, k, t} \times S T_{c, k, t}^{ \pm}\right) \times C U_{c, k, t}^{ \pm} \\
& +\sum_{c=1}^{2} \sum_{k=1}^{8} \sum_{t=1}^{5} \sum_{q=1}^{3}\left(E G A_{c, k, t}^{ \pm}+E C_{c, k, t}^{ \pm} \times Y C_{c, k, t} \times S T_{c, k, t}^{ \pm}\right) \times\left(C P_{c, t, q}^{ \pm}+C E_{c, t, q}^{ \pm} / S T_{c, k, t}^{ \pm}-S U_{c, k, t}^{ \pm}\right)
\end{aligned}
$$

Constraints will include resource availability, electricity demand-supply balance, capacity expansion as well as environmental requirement. They can be formulated as follows: 
(1) Resource availability constraints:

$$
\begin{aligned}
& N Y L_{c, j, t}^{ \pm} \leq A R_{c, j, t}^{ \pm} \\
& E G A_{c, k=1, t}^{ \pm} \times F E_{c, k=1, t}^{ \pm} \leq N Y L_{c, j=1, t}^{ \pm} \\
& E G A_{c, k=2, t}^{ \pm} \times F E_{c, k=2, t}^{ \pm} \leq N Y L_{c, j=3, t}^{ \pm}
\end{aligned}
$$

(2) Capacity limitation constraint of electricity-conversion facilities:

$$
E G A_{c, k, t}^{ \pm} \leq\left(R C_{c, k, t}^{ \pm}+\left(E C_{c, k, t}^{ \pm}+\left(r^{m}+\frac{h_{r}-h_{r}^{\prime}}{3}\right) \times(1-\beta)\right) \times Y C_{c, k, t}\right) \times S T_{c, k, t}^{ \pm}
$$

(3) Constraints of electricity demand:

$$
\begin{aligned}
& \sum_{k=1}^{8} E G A_{c=1, k, t}^{ \pm} \times\left(1-\mathrm{ZL}_{c=1, k, \mathrm{t}}^{ \pm}\right) \times \mathrm{TE}_{c=1, k, t}^{ \pm}+P E_{c=1, t}^{ \pm} \\
& \geq\left(\text {Demand }^{q_{1}}\right)_{c=1, t}^{ \pm}-\left(t^{m}+\frac{\vartheta_{t}-\vartheta_{t}^{\prime}}{3}\right) \times(1-\alpha) \\
& \sum_{k=1}^{8} E G A_{c=2, k, t}^{ \pm} \times\left(1-\mathrm{ZL}_{c=2, k, \mathrm{t}}^{ \pm}\right) \times \mathrm{TE}_{c=2, k, t}^{ \pm}+P E_{c=2, t}^{ \pm} \\
& \geq\left(\text {Demand }^{q_{2}}\right)_{c=2, t}^{ \pm}-\left(t^{m}+\frac{\vartheta_{t}-\vartheta_{t}^{\prime}}{3}\right) \times(1-\alpha) \\
& C\left(1-p_{1}, 1-p_{2}\right)=1-p
\end{aligned}
$$

(4) Constraint of pollutant emissions:

$$
\sum_{c=1}^{2} \sum_{k=1}^{8} \sum_{t=1}^{5} E G A_{c, k, t}^{ \pm} \times A M R_{c, k, t, q}^{ \pm} \leq E S_{c, t, q}^{ \pm}, \quad \forall c, t, q
$$

(5) Constraints for capacity expansion:

$$
\begin{aligned}
& Y C_{k, t}\left\{\begin{array}{l}
=1 ; \quad \text { if capacity expasion is undertaken } \\
=0 ; \quad \text { if otherwise }
\end{array}\right\} \\
& R C_{c, k, t}^{ \pm}+E C_{c, k, t}^{ \pm} \times Y C_{k, t} \leq \text { Cap_ } U_{k, t}^{ \pm} \\
& \sum_{c=1}^{2} \sum_{k=1}^{8} \sum_{t=1}^{5}\left(R C_{c, k, t}^{ \pm}+E C_{c, k, t}^{ \pm} \times Y C_{k, t}\right) \leq \text { Cap }_{-} T^{ \pm}
\end{aligned}
$$

(6) Nonnegative constraints:

$$
N Y L_{c, j, t}^{ \pm}, P E_{c, t}^{ \pm}, E G A_{c, k, t}^{ \pm} \geq 0 ; \forall c, k, j, t
$$

The detailed nomenclature for parameters and variables is provided in Appendix B. In this study, the representative economic and technical data were obtained from Beijing Statistical Yearbook, 
Tianjin Statistical Yearbook, China Statistical Yearbook, Ministry of Industry and Information Technology of the People's Republic of China, government official reports, as well as literature survey [43-46]. Table 1 provides energy consumption rate (i.e. the TJ total energy consumption or utilization for per GWh electrical power generated) for each power-conversion technique. Many factors affecting energy-consumption rate of power plants involve combustion temperature, fuel types, carbon content of flying ash and furnace slag, combustion of control and adjustment, and smoke extraction temperature [47]. These lead to uncertain energy consumption rate, which are expressed as intervals. Table 2 presents the fixed and variable costs for each power-capacity expansion, which are not available as deterministic values. For instance, the investment for expanding power-conversion facilities could be affected by numbers of factors (e.g., finance investment, facility service life, labor fee and operation condition) [48]. Besides, activities for capacity expansion may involve volumes of capitals from multiple sources, leading to different interest rates; from a long-term planning point of view, the interest and inflation rates may both keep fluctuating due to the effects from many factors such as socio-economic, technical, legislational, institutional and political aspects.

Place Tables 1 and 2 here

Electricity demand is subject to a range of factors such as population growth, changing technology, economic conditions, prevailing weather conditions as well as the general randomness in individual usage [18]. In this study, the historical data of electricity consumption in years 1996-2016 were used for determining the marginal cumulative distribution function (CDF) of random variables and a joint CDF for measuring statistical dependence between them. In detail, the annual electricity growth rates of Beijing and Tianjin in years 1996-2016 were used for generating the marginal probability distributions; Kolmogorov-Smirnov tests were used for evaluating the generated probability distributions if they were best fitted; Pearson's linear correlation tests were used for confirming the random variables if they were mutually correlated [15]. The joint CDF for the annual electricity growth rates of Beijing and Tianjin was obtained through using Gumbel-Hougaard Copula, as detailed in Figure 2. In this study, the planning horizon is five years. Besides, three joint constraint-violation levels (i.e. $p=0.05,0.1$ and 0.2 ) 
and fifteen representative scenarios (i.e. S1, S2, .., S15) of individual constraint-violation levels $\left(p, p_{1}, p_{2}\right)$ were illustrated in Table 3, where $p$ denoted the joint constraint-violation level; $p_{1}$ and $p_{2}$ denoted the individual constraint-violation levels corresponding to the annual electricity growth rates of Beijing and Tianjin, respectively. Four minimum satisfaction levels of flexible constraints (i.e. $\alpha=\beta=0,0.3,0.6$ and 0.9 ) were examined associated with each of the representative fifteen scenarios.

Place Figure 2 and Table 3 here

\section{Result and Uncertainty Analysis}

\subsection{Result analysis}

Beijing is a typical power-import city; its domestic electricity production is far below the city's electricity consumption which occupies lower than $60 \%$. Compared to Beijing, Tianjin is a self-supporting based city, the electricity generated by domestic production accounts for $75.6 \%$. Besides, fossil-based power takes the primary role for the domestic electricity production of the RES of Beijing and Tianjin. As shown in Figure 3, the share of electricity generated by fossil energies occupied [92.8, 93.3] \% of the total RES, [87.6, 88.5] \% of Beijing and [95.5, 95.7] \% of Tianjin, respectively. Although renewable energies occupied minor share to the total electricity production over the planning horizon, the electricity-supply pattern would still tend to the slight change from fossil energies to renewable energies in each planning year in accordance with the implement of REDP. For example, the increment rate of renewable energies from year 1 to year 5 would be $[9.5,9.7] \%$ in Beijing, $[0.8,0.9] \%$ in Tianjin and $[2.9,3.0] \%$ for the entire RES, respectively.

Place Figure 3 here

Figure 4 shows the pollutant emissions (i.e. $\mathrm{SO}_{2}, \mathrm{NO}_{\mathrm{x}}$ and $\mathrm{PM}_{10}$ ) of $\mathrm{RES}$ under different emitters 
over the planning horizon. Summarily, coal-fired power is the primary emitter for the entire power-conversion facilities owing to the higher pollutant discharge coefficient and lower coal price. For example, for the entire RES, Tianjin occupied the dominated role of pollutant emissions while Beijing merely accounted for minor percent. This is mainly ascribe to the facts that: (a) for Beijing, the coal-fired power would be totally reformed to gas-fired power by the end of 2016, which would lead to the pollutant emissions of Beijing declined greatly; (b) in accordance with the implement of REDP, lots of electricity in Beijing and Tianjin would be substituted from fossil energies to renewable energies or power import, which would reduce some pollutant emissions; (c) Tianjin is a self-supporting city, where its self-supporting rate reached $75.6 \%$, and most of the domestic electricity-production were generated by fossil energies, especially for coal. For each planning year, the pollutant emissions would be reduced with time in response to the implement of air pollution controls, reform of coal-burning boils, stimulation of renewable energy resources, as well as improvement of energy transmission capacities and efficiencies in the RES.

Place Figure 4 here

\subsection{Uncertainty analysis}

In this study, three joint constraint-violation levels (i.e. $p=0.05,0.1$ and 0.2 ) of violating electricity demand of RES in Beijing and Tianjin were considered to reflect energy demand-supply risk. Under each joint constraint-violation level, four (i.e. $p_{1}=0.01,0.02,0.03$ and $0.04 ; p_{1}=0.02,0.04,0.06$ and 0.08 ) or seven scenarios (i.e. $p_{1}=0.01,0.03,0.06,0.09$, $0.12,0.15$ and 0.18 ) of individual constraint-violation levels were selected to verify the interaction of electricity demands between the urban cities of Beijing and Tianjin. Four satisfaction degrees (i.e. $\alpha=\beta=0,0.3,0.6$ and 1) of flexible constraints on fixed and variable costs were used for dealing with soft constraints and flexibility on target value of goals.

Uncertainties related to different scenarios would result in different electricity-supply structures and then generate various system costs. As shown in Figure 5, when $p=0.1$ and $\alpha=0$, the 
system cost would be varied with different scenarios and the lowest system would be $\$[1.99$, $2.06] \times 10^{12}$ under $\mathrm{S} 8$; when $\mathrm{p}=0.2$ and $\alpha=0$, the system cost would be decreased from S9 to S14 (i.e. $\$[1.90,1.96] \times 10^{12}$ ) and then increased until S15. Summarily, the system costs under $p$ $=0.1$ were higher than that in $\mathrm{p}=0.2$ under each satisfaction level. This is because, $\mathrm{p}$ levels indicate the joint violation levels of not satisfying the electricity demand of the entire RES, a lower p level (i.e. a higher electricity demand) corresponding to an increased reliability in fulfilling the RES requirements, which led to a higher system cost; conversely, a higher p level (i.e. a lower electricity demand) corresponding to a decreased security in ensuring the effective operation of RES, thus leading to a lower system cost. Results disclosed that there existed a tradeoff between the system cost and the joint constraint-violation risk. Besides, by making a comparison of various scenarios at the same joint constraint-violation level, we could find that the system cost would be varied with different individual constraint-violation levels and the minimum system cost would occur in the scenario that $p_{1}=p_{2}$. Solutions of different individual constraint-violation levels were effective for not only providing in-depth analyses for exploring the impacts of random variables and their interactions to the system cost, but also reaching equilibriums between system demand-supply reliability and system cost.

Place Figure 5 here

Since the electricity demand of RES is much beyond its self-supporting generation, electricity of outsourcing would become of great importance to compensate the local electricity shortage. As shown in Figures 5-8, we could find that different $\alpha$ and $\beta$ levels would lead to different system costs, imported electricity, varied domestic electricity-supply patterns, as well as changed pollutant emissions. For example, as shown in Figure 8, the variations for $\mathrm{NO}_{\mathrm{x}}$ in Beijing between $\alpha=\beta=0$ and $\alpha=\beta=0.9$ would be reached $[119.7,135.3]$ tonne of gas-fired power, [96.0, 100.8] tonne of biomass power and [318.4, 334.3] tonne of waste power, respectively. And the system cost, imported electricity and renewable energy-based electricity would be ascended with the $\alpha$ and $\beta$ levels. This is because, $\alpha$ and $\beta$ levels were respectively employed to the constraints of electricity demand-supply balance and capacity limitation constraint of electricity-conversion facilities. High $\alpha$ and $\beta$ levels would correspond to decision maker's desire 
to achieve the minimized system cost with high violation degrees in soft constraints, thus resulting in a low satisfactory attitude to prohibiting not opened facilities costs. On the contrary, low $\alpha$ and $\beta$ levels would correspond to the decision maker's desire to achieve the minimized system cost with low violation degrees in soft constraints, thus leading to a high satisfactory attitude to prohibiting not opened facilities costs. Summarily, based on the multiple uncertainties that collectively employed to the CFSP-RES, the variation of minimum system cost would be changed from $\$[1.90,1.96] \times 10^{12}$ (i.e. S14 under $\alpha=\beta=0$ ) to $\$[2.20,2.28] \times 10^{12}$ (i.e. S1 under $\alpha=\beta=0.9$ ), and the variation of system cost can be reached $16.3 \%$.

Place Figures 6-8 here

\section{Discussion}

\subsection{Impacts of REDP policy}

Figure 9 depicts the pollutant emissions with- and without implementing REDP in years of 2016-2020. In detail, without implementing the REDP, the total pollutant emissions of $\mathrm{SO}_{2}, \mathrm{NO}_{\mathrm{x}}$ and $\mathrm{PM}_{10}$ in the planning horizon would be $[64.9,72.6] \times 10^{3}$ tonne, $[270.9,318.3] \times 10^{3}$ tonne and $[241.1,268.0] \times 10^{3}$ tonne, respectively; comparatively, after the implement of REDP, the total pollutant emissions of $\mathrm{SO}_{2}, \mathrm{NO}_{x}$ and $\mathrm{PM}_{10}$ would be $[62.7,67.1] \times 10^{3}$ tonne, $[263.7,305.2]$ $\times 10^{3}$ tonne and $[224.3,237.2] \times 10^{3}$ tonne, respectively. Consequently, the reductive rates of pollutant emissions would be $[3.3,7.6] \%$ of $\mathrm{SO}_{2},[2.7,4.1] \%$ of $\mathrm{NO}_{\mathrm{x}}$ and $[7.0,11.5] \%$ of $\mathrm{PM}_{10}$, respectively. Since the RES including two urban cities, the detailed pollutant emissions in each urban city would be different. The changed variations of pollutant emissions between Beijing and Tianjin were mainly ascribe to the facts that: (a) after the totally reformation of coal-fired boilers, there would be no coal-fired power-conversion facilities in Beijing; besides, based on the REDP, the added biomass and waste powers would generate more pollutant emissions compared to the current status; (b) Tianjin is a fossil-energy based city, where coal-fired power occupied the dominated role; although some pollutants would be more generated in response to the added capacities of biomass and waste powers, the pollutants emitted by the coal-fired power would be 
largely reduced based on the air pollution-control plan in years of 2016-2020, thus leading to the decline of total pollutant emissions. Moreover, the primary emitter for the air-pollutants in Beijing would be the transportation sector after the shutdown of coal-fired power plants, and the air-pollutants in Tianjin are mainly derived from the sectors of industry and transportation. Therefore, additional efforts need to be undertaken to reduce the pollutant emissions and improve the air quality with a sustainable way (e.g., implement of air quality plans, development of electric vehicles, improvement of energy utilization efficiencies and upgradation of power transmission infrastructures, ae well as adoption of regional co-control plans toward power-supply security and air-pollution mitigation) $[3,49,50]$.

\subsection{Comparison with the conventional JCP}

Figure 5 also indicates that when a joint probability level is given (i.e. $p=0.2$ ), the system costs would increase with $\mathrm{p}_{2}$ (i.e. violating the second chance constraint) or decrease with $\mathrm{p}_{1}$ (i.e. violating the first chance constraint) under scenarios of S9-S14; conversely, the system costs would decrease with $\mathrm{p}_{2}$ or increase with $\mathrm{p}_{1}$ under scenario of $\mathrm{S} 15$. And the minimum system cost would occur in the scenario that $p_{1}=p_{2}$. For example, when $\mathrm{p}=0.2$ and $\alpha=\beta=0$, the system costs corresponding to $\mathrm{p}_{1}=0.01,0.03,0.06$ and 0.09 would be $\$[2.02,2.09] \times 10^{12}, \$[1.97$, $2.04] \times 10^{12}, \$[1.94,2.00] \times 10^{12}$ and $\$[1.91,1.98] \times 10^{12}$, respectively. An increased violating level of $\mathrm{p}_{1}$ may cause an expanded decision space for a given $\mathrm{p}$ level, and thus a lower system cost may be produced; conversely, an increased violating level of $\mathrm{p}_{2}$ may lead to a reduced decision space for a given $\mathrm{p}$ level, which may lead to a higher system cost. Consequently, some differences among system costs would be generated owing to different marginal probability levels even if at a fixed joint probability level. In other words, there exist a tradeoff between the system cost and marginal probability levels. However, in conventional JCP problems, previous studies indicated that the marginal probability levels had no effective influences on system costs under a fixed joint probability level $[51,52]$. The previous studies were limited to the assumption that all the stochastic variables were independently and normally distributed with known means and variances. This assumption was not justified and might encounter difficulty in application to planning real-world RES problems. Besides, some studies for JCP problems indicated that each marginal probability level should be satisfied with the assumption that $p_{1}+p_{2}<=p \quad[53,54]$. 
These studies were based on the assumption that all the marginal probability levels were followed the determinative linear relationship. However, as shown in CFSP-RES, the marginal probability levels were not followed as determinatively linear relationships and the range of marginal probability levels might not be restricted as the assumption of $p_{1}+p_{2}<=p \quad$ (e.g., $\mathrm{p}_{1}=$ 0.15 and $\mathrm{p}_{2}=0.157$ in $\mathrm{S} 14 ; \mathrm{p}_{1}=0.18$ and $\mathrm{p}_{2}=0.116$ in S15). In addition, in the present study (CFSP-RES), the random variables may have any same or different forms of probability distributions and they may be correlated with each other, and the interactive relationships of all the groups of marginal probability levels can be obtained based on the copula functions. Therefore, the CFSP approach proposed in this study is not limited to the assumptions, and thereby can be applied to a wider range of problems than the previous studies.

\section{Conclusions}

In this study, a copula-based flexible-stochastic programming (CFSP) method has been proposed for planning the energy system within a regional scale under multi-uncertainty. CFSP simultaneously reflects interactive features of random variables and deals with uncertain parameters in target value of goals and soft constraints. Its applicability has been verified for planning RES of the urban agglomeration of Beijing and Tianjin. Based on the proposed CFSP method, a CFSP-RES model has been formulated. Issues of energy demand-supply security, minimum system cost and environment mitigation, as well as multiple uncertainties are reflected in the CFSP-RES. Several findings can be revealed as follows: (a) uncertainties existed in the RES lead to changes of decision variables and system costs, and the variation of system cost can be reached $16.3 \%$ based on the jointly impacts of multiple uncertainties; (b) by making a comparison of various scenarios at the same joint constraint-violation level, the minimum system cost can occur in the scenario that $p_{1}=p_{2} ;$ (c) interactions of electricity demands have significant impacts on system costs, electricity-supply patterns and pollutant emissions.

Compared to the impacts of REDP policy, the CFSP-RES model can help reduce the pollutant emissions and improve the air quality with a sustainable way. In detail, the reductive rates of pollutant emissions in the RES can be reached $[3.3,7.6] \%$ of $\mathrm{SO}_{2},[2.7,4.1] \%$ of $\mathrm{NO}_{\mathrm{x}}$ and $[7.0$, 11.5] \% of $\mathrm{PM}_{10}$, respectively. Besides, compared with the conventional JCP problems, the 
CFSP-RES model could have wider applications and might not limited to some unjustified assumptions. In detail, the CFSP-RES model could not only obtain all the groups of marginal probability levels at any linear or nonlinear relationships under a given joint constraint-violation

level through using copula functions, but also reveal the impacts of interactive random variables on the system outputs even having different probability distributions and previously unknown correlations. Therefore, the CFSP-RES model proposed in this study is not limited to the assumptions, and thereby can be applied to a wider range of problems than the previous studies.

However, there are several assumptions for formulating the CFSP-RES model, which may lead to some limitations for planning the RES of Beijing and Tianjin. Firstly, the historical data in years 1996-2016 were used for fitting the marginal probability distributions of the availability of electricity demands; in probability theory, according to law of large numbers and central limit theorem, any random event approximates a probabilistic distribution when the samples' number is greater than a certain number [55]. Secondly, capacity expansion of each power-conversion facility in the planning horizon is limited to the condition of finance investment and facility service life $[42,47]$. Thirdly, each community in the urban city has the same economy and energy structures in order to satisfy the mathematical expression capacity and improve the computational efficiency of the CFSP-RES model [48]. Besides, several potential limitations and further improvements should be addressed in future study: (a) CFSP-RES model merely deals with fuzzy sets in the soft constraints, it may encounter difficulties in handling ambiguous parameters presented in the objective function; (b) CFSP-RES could not suitable for large-scale and more complicated problems, enhanced robust methods should be adopted to deal with such increased complexities and uncertainties. Therefore, improvements would be desirable in further investigations to mitigate these limitations.

\section{Acknowledgements}

This research was supported by Beijing Natural Science Foundation of China (L160011), State Grid Science \& Technology Project (5217L017000N) and the State Scholarship Fund of China (201606730023). The authors are grateful to the editors and the anonymous reviewers for their insightful comments and suggestions. 


\section{References}

[1] BP Energy Outlook, 2017. The role Africa will play in driving global energy demand. Beyond 2035: Africa. Available at: https://www.bp.com/content/dam/bp/pdf/energy-economics/energy-outlook-2017/bp-energyoutlook-2017.pdf.

[2] International Energy Agency (IEA), 2016. World Energy Outlook Special Report 2016: Energy and Air Pollution. Available at: https://www.iea.org/publications/freepublications/publication/weo-2016-special-report-energ y-and-air-pollution.html.

[3] Yu L. Li YP, Huang GH, Shan BG. An interval-possibilistic basic-flexible programming method for air quality management of municipal energy system through introducing electric vehicles. Science of the Total Environment. 2017;593-594:418-429.

[4] Hemmati R, Saboori H, Jirdehi MA. Stochastic planning and scheduling of energy storage systems for congestion management in electric power systems including renewable energy resources. Energy. 2017;133:380-387.

[5] Cano EL, Moguerza JM, Alonso-Ayuso A. A multi-stage stochastic optimization model for energy systems planning and risk management. Energy and Buildings. 2016;110:49-56.

[6] Odetayo B, MacCormack J, Rosehart WD, Zareipour H. A chance constrained programming approach to integrated planning of distributed power generation and natural gas network. Electric Power Systems Research. 2017;151:197-207.

[7] Park H, Baldick R. Multi-year stochastic generation capacity expansion planning under environmental energy policy. Applied Energy. 2016;183:737-745.

[8] Nematian J. An extended two-stage stochastic programming approach for water resources management under uncertainty. Journal of Environmental Informatics. 2016;27(2):72-84.

[9] Simic V. A multi-stage interval-stochastic programming model for planning end-of-life vehicles allocation. Journal of Cleaner Production. 2016;115:366-381.

[10] Esmaeeli M, Kazemi A, Shayanfar H, Chicco G, Siano P. Risk-based planning of the distribution network structure considering uncertainties in demand and cost of energy. Energy. 2017;119:578-587.

[11] Parvizimosaed M, Farmani F, Monsef H, Rahimi-Kian A. A multi-stage smart energy 
management system under multiple uncertainties: a data mining approach. Renewable Energy. 2017;102,Part A:178-189.

[12] Sun W, Huang GH, Lv Y, Li GC. Inexact joint-probabilistic chance-constrained programming with left-hand-side randomness: an application to solid waste management. European Journal of Operational Research. 2013;228(1):217-225.

[13] Excoffier M, Gicquel C, Jouini O. A joint chance-constrained programming approach for call center workforce scheduling under uncertain call arrival forecasts. Computers \& Industrial Engineering. 2016;96:16-30.

[14] Kamjoo A, Maheri A, Putrus GA. Chance constrained programming using non-Gaussian joint distribution function in design of standalone hybrid renewable energy systems. Energy. 2014;66:677-688.

[15] Chen F, Huang GH, Fan YR, Wang S. A copula-based chance-constrained waste management planning method: an application to the city of Regina, Saskatchewan, Canada. Journal of the Air \& Waste Management Association. 2016;66:307-328.

[16] Chen F, Huang GH, Fan YR, Chen JP. A copula-based fuzzy chance-constrained programming model and its application to electric power generation systems planning. Applied Energy. 2017;187:291-309.

[17] da Silva AF, Marins FAS. A fuzzy goal programming model for solving aggregate production-planning problems under uncertainty: a case study in a Brazilian sugar mill. Energy Economics. 2014;45:196-204.

[18] Yu L, Li YP, Huang GH. A fuzzy-stochastic simulation-optimization model for planning electric power systems with considering peak-electricity demand: A case study of Qingdao, China. Energy. 2016;98:190-203.

[19] Jin L, Huang GH, Fan YR, Wang L, Wu T. A pseudo-optimal inexact stochastic interval T2 fuzzy sets approach for energy and environmental systems planning under uncertainty: a case study for Xiamen City of China. Applied Energy. 2015;138:71-90.

[20] Pishvaee MS, Khalaf MF. Novel robust fuzzy mathematical programming methods. Applied Mathematical Modelling. 2016;40:407-418.

[21] Yu L, Li YP, Huang GH, An CJ. A robust flexible-probabilistic programming method for planning municipal energy system with considering peak-electricity price and electric vehicle. Energy Conversion and Management. 2017;137:97-112. 
[22] Huang GH. IPWM: an interval parameter water quality management model. Engineering Optimization. 1996;26(2):79-103.

[23] Simic V, Dabic-Ostojic S. Interval-parameter chance-constrained programming model for uncertainty-based decision making in tire retreading industry. Journal of Cleaner Production. 2017;167:1490-1498.

[24] Nelsen RB. An introduction to copulas. Second Edition. New York: Springer. 2006.

[25] Yager RR. Conditional information using copulas with an application to decision making. Fuzzy Sets and Systems. 2015;272:89-101.

[26] Sun C, Bie ZH, Xie M, Jiang JF. Fuzzy copula model for wind speed correlation and its application in wind curtailment evaluation. Renewable Energy. 2016;93:68-76.

[27] Kayalar DE, Küçüközmenb CC, Selcuk-Kestel AS. The impact of crude oil prices on financial market indicators: copula approach. Energy Economics. 2017;61:162-173.

[28] Pircalabu A, Hvolby T, Jung J, Høg E. Joint price and volumetric risk in wind power trading: a copula approach. Energy Economics. 2017;62:139-154.

[29] Su JX, Furman E. Multiple risk factor dependence structures: copulas and related properties. Insurance: Mathematics and Economics. 2017;74:109-121.

[30] Charnes A, Cooper WW, Kirby MJL. 1971. Chance constrained programming: an extension of statistical method. Optimizing Methods in Statistics Academic Press. 1971;391-402.

[31] Infanger G, Morton DP. Cut sharing for multistage stochastic linear programs with interstage dependency. Mathematical Programming. 1996;75:241-256.

[32] Charnes A, Cooper WW. Response to decision problems under risk and chance constrained programming: dilemmas in the transitions. Management Science. 1983;29(6):750-753.

[33] Pishvaee MS, Razmi J, Torabi SA. Robust possibilistic programming for socially responsible supply chain network design: a new approach. Fuzzy Sets and Systems. 2012;206:1-20.

[34] Cadenas JM, Verdegay JL. Using fuzzy numbers in linear programming. IEEE Transactions on Systems, Man, and Cybernetics, Part B (Cybernetics). 1997;27(6):1016-1022.

[35] Peidro D, Mula J, Poler R, Verdegay JL. Fuzzy optimization for supply chain planning under supply, demand and process uncertainties. Fuzzy Sets and Systems. 2009;160(18):2640-2657.

[36] Yager RR. Ranking fuzzy subsets over the unit interval, in Proceedings of 17th IEEE 
International Conference on Decision and Control, San Diego, CA, 1979;1435-1437.

[37] Yager RR. A procedure for ordering fuzzy subsets of the unit interval. Information Sciences. $1981 ; 24(2): 143-161$.

[38] Boloukat MHS, Foroud AA. Stochastic-based resource expansion planning for a grid-connected microgrid using interval linear programming. Energy. 2016;113:776-787.

[39] Moret S, Gironèsa VC, Bierlaireb M, Maréchal F. Characterization of input uncertainties in strategic energy planning models. Applied Energy. 2017;202:597-617.

[40] Yu L, Li YP, Huang GH, Li YF, Nie S. Planning carbon dioxide mitigation of Qingdao's electric power systems under dual uncertainties. Journal of Cleaner Production. 2016;139:473-487.

[41] Jin SW, Li YP, Nie S, Sun J. The potential role of carbon capture and storage technology in sustainable electric-power systems under multiple uncertainties. Renewable and Sustainable Energy Reviews. 2017;80:467-480

[42] Li YP, Huang GH. Electric-power systems planning and greenhouse-gas emission management under uncertainty. Energy Conversion and Management. 2012;57:173-182.

[43] Beijing Statistical Yearbook, 2016. Statistics Bureau of Beijing Municipality. Available at: http://www.bjstats.gov.cn/nj/main/2016-tjnj/zk/indexch.htm.

[44] Nie S, Huang CZ, Huang GH, Li YP, Chen JP, Fan YR, Cheng GH. Planning renewable energy in electric power system for sustainable development under uncertainty - a case study of Beijing. Applied Energy. 2016;162:772-786.

[45] Tianjin Statistical Yearbook, 2016. Statistics Bureau of Tianjin Municipality. Available at: http://www.stats-tj.gov.cn/Item/26545.aspx.

[46] Hebei Economic Yearbook, 2016. Hebei Provincial Bureau of Statistics. http://www.hetj.gov.cn/res/nj2016/indexch.htm.

[47] Jin SW, Li YP, Huang GH. An interactive optimization model for energy systems planning associated with clean-energy development under uncertainty. International Journal of Energy Research. 2017;41:482-501.

[48] Zhu Y, Li YP, Huang GH. Planning carbon emission trading for Beijing's electric power systems under dual uncertainties. Renewable and Sustainable Energy Reviews. 2013;23:113-128.

[49] Miranda AL, Ferreira J, Silveira C, Relvas H, Duque L, Roebeling P, Lopes M, Costa S, 
Monteiro A, Gama C, Sá E, Borrego C, Teixeira, JP. A cost-efficiency and health benefit approach to improve urban air quality. Science of the Total Environment. 2016;569-570:342-351.

[50] Zeng A, Mao XQ, Hu T, Xing YK, Gao YB, Zhou J, Qian Y. Regional co-control plan for local air pollutants and $\mathrm{CO} 2$ reduction: Method and practice. Journal of Cleaner Production. 2017;140:1226-1235.

[51] Zulueta Y, Rodriguez RM, Bello R, Martinez L. A hesitant heterogeneous approach for environmental impact significance assessment. Journal of Environmental Informatics. 2017;29(2):74-87.

[52] Li YP, Huang GH. A stochastic-fuzzy programming model with soften constraints for electricity generation planning with greenhouse-gas abatement. International Journal of Energy Research. 2013;37(8):843-856.

[53] Bentaha ML, Battaia O, Dolgui A, Hu SJ. Second order conic approximation for disassembly line design with joint probabilistic constraints. European Journal of Operational Research. 2015;247(3):957-967.

[54] Zhang CL, Li M, Guo P. An interval multistage joint-probabilistic chance-constrained programming model with left-hand-side randomness for crop area planning under uncertainty. Journal of Cleaner Production. 2017;167:1276-1289.

[55] Fan YR, Huang WW, Li YP, Huang GH, Huang K. A coupled ensemble filtering and probabilistic collocation approach for uncertainty quantification of hydrological models. Journal of Hydrology. 2015;530:255-272.

[56] Huang GH, Loucks DP. An inexact two-stage stochastic programming model for water resources management under uncertainty. Civil Engineering and Environmental Systems. 2000;17:95-118. 


\section{List of Table Captions}

Table 1. Energy consumption rate for each power-conversion technique (unit: TJ/GWh)

Table 2. Fixed and variable costs for each power-capacity expansion

Table 3. Selected values of joint cumulative distribution, conditional cumulative distribution and marginal cumulative distributions as well as corresponding values of random variables 


\section{List of Figure Captions}

Figure 1 . The study area

Figure 2. Joint cumulative distribution function for annual electricity consumption growth rates of Beijing and Tianjin obtained through using Gumbel-Hougaard Copula

Figure 3. Electricity supply pattern

Figure 4. Pollutant emissions under different emitters

Figure 5. System costs under different scenarios

Figure 6. Imported electricity under different scenarios

Figure 7. Electricity generated by renewable energies under different $\alpha$ and $\beta$ levels

Figure 8. Pollutant emissions under different $\alpha$ and $\beta$ levels

Figure 9. Pollutant emissions with- and without implementing REDP 
Table 1. Energy consumption rate for each power-conversion technology (unit: $\mathrm{TJ} / \mathrm{GWh}$ )

\begin{tabular}{llllll}
\hline Year & 1 & 2 & 3 & 4 & 5 \\
\hline Coal-fired & {$[11.00,13.00]$} & {$[10.90,12.90]$} & {$[10.80,12.80]$} & {$[10.70,12.70]$} & {$[10.60,12.60]$} \\
Gas-fired & {$[10.30,12.30]$} & {$[10.25,12.25]$} & {$[10.20,12.20]$} & {$[10.15,12.15]$} & {$[10.10,12.10]$} \\
Hydro & {$[3.50,4.00]$} & {$[3.40,3.90]$} & {$[3.30,3.80]$} & {$[3.20,3.70]$} & {$[3.10,3.60]$} \\
Wind & {$[0.12,0.14]$} & {$[0.11,0.13]$} & {$[0.10,0.12]$} & {$[0.09,0.11]$} & {$[0.08,0.10]$} \\
Photovoltaic & {$[4.25,4.75]$} & {$[4.24,4.74]$} & {$[4.23,4.73]$} & {$[4.22,4.72]$} & {$[4.21,4.71]$} \\
Biomass & {$[5.50,6.00]$} & {$[5.48,5.98]$} & {$[5.46,5.96]$} & {$[5.44,5.94]$} & {$[5.42,5.92]$} \\
Waste & {$[4.40,4.90]$} & {$[4.35,4.85]$} & {$[4.30,4.80]$} & {$[4.25,4.75]$} & {$[4.20,4.70]$} \\
Pumped-storage & {$[2.00,2.20]$} & {$[1.95,2.15]$} & {$[1.90,2.10]$} & {$[1.85,2.05]$} & {$[1.80,2.00]$} \\
\hline
\end{tabular}


Table 2. Fixed and variable costs for each power-capacity expansion

\begin{tabular}{|c|c|c|c|c|c|}
\hline Year & 1 & 2 & 3 & 4 & 5 \\
\hline \multicolumn{6}{|c|}{ Fixed investment $\left(\$ 10^{9}\right)$} \\
\hline Coal-fired & {$[0.37,0.39]$} & {$[0.39,0.41]$} & {$[0.40,0.42]$} & {$[0.42,0.44]$} & {$[0.43,0.45]$} \\
\hline Gas-fired & {$[0.35,0.37]$} & {$[0.37,0.39]$} & {$[0.38,0.40]$} & {$[0.39,0.41]$} & {$[0.41,0.43]$} \\
\hline Hydro & {$[0.70,0.74]$} & {$[0.71,0.75]$} & {$[0.72,0.76]$} & {$[0.73,0.77]$} & {$[0.74,0.78]$} \\
\hline Wind & {$[0.91,0.96]$} & {$[0.93,0.98]$} & {$[0.95,1.00]$} & {$[0.97,1.02]$} & {$[0.99,1.04]$} \\
\hline Photovoltaic & {$[0.96,1.01]$} & {$[0.98,1.03]$} & {$[1.00,1.05]$} & {$[1.02,1.07]$} & {$[1.04,1.09]$} \\
\hline Biomass & {$[0.41,0.44]$} & {$[0.42,0.45]$} & {$[0.43,0.46]$} & {$[0.44,0.47]$} & {$[0.45,0.48]$} \\
\hline Waste & {$[0.25,0.27]$} & {$[0.26,0.28]$} & {$[0.26,0.28]$} & {$[0.27,0.29]$} & {$[0.28,0.30]$} \\
\hline Pumped-storage & {$[0.35,0.37]$} & {$[0.36,0.38]$} & {$[0.36,0.38]$} & {$[0.37,0.39]$} & {$[0.37,0.39]$} \\
\hline \multicolumn{6}{|c|}{ Variable operation and maintenance cost $\left(\$ 10^{9} / \mathrm{GW}\right)$} \\
\hline Coal-fired & {$[0.79,0.83]$} & {$[0.80,0.84]$} & {$[0.81,0.85]$} & {$[0.82,0.86]$} & {$[0.83,0.87]$} \\
\hline Gas-fired & {$[0.74,0.78]$} & {$[0.75,0.79]$} & {$[0.76,0.80]$} & {$[0.77,0.81]$} & {$[0.78,0.82]$} \\
\hline Hydro & {$[1.80,1.90]$} & {$[1.83,1.93]$} & {$[1.85,1.95]$} & {$[1.88,1.98]$} & {$[1.90,2.00]$} \\
\hline Wind & {$[2.19,2.29]$} & {$[2.20,2.30]$} & {$[2.21,2.31]$} & {$[2.22,2.32]$} & {$[2.23,2.33]$} \\
\hline Photovoltaic & {$[2.24,2.34]$} & {$[2.26,2.36]$} & {$[2.29,2.39]$} & {$[2.31,2.41]$} & {$[2.34,2.44]$} \\
\hline Biomass & {$[0.82,0.86]$} & {$[0.83,0.87]$} & {$[0.84,0.88]$} & {$[0.85,0.89]$} & {$[0.86,0.90]$} \\
\hline Waste & {$[0.49,0.52]$} & {$[0.50,0.53]$} & {$[0.51,0.54]$} & {$[0.52,0.55]$} & {$[0.53,0.56]$} \\
\hline Pumped-storage & {$[0.90,0.95]$} & {$[0.91,0.96]$} & {$[0.92,0.97]$} & {$[0.93,0.98]$} & {$[0.94,0.99]$} \\
\hline
\end{tabular}


Table 3. Selected values of joint cumulative distribution, conditional cumulative distribution and marginal cumulative distributions as well as corresponding values of random variables

\begin{tabular}{|c|c|c|c|c|c|c|c|c|c|c|c|}
\hline Scenarios & $H_{x, y}(x, y)$ & $H_{y / x}(y \mid X \leq x)$ & $F_{x}(x)$ & $G_{y}(\mathrm{y})$ & & $x(\%)$ & & $y(\%)$ & & $\left(p, p_{1}, p_{2}\right)$ & \\
\hline & & & & Lower & Upper & Lower & Upper & Lower & Upper & Lower & Upper \\
\hline S1 & 0.950 & 0.960 & 0.990 & 0.950 & 0.950 & 13.469 & 13.712 & 14.103 & 14.453 & $(0.05,0.01,0.050)$ & $(0.05,0.01,0.050)$ \\
\hline $\mathrm{S} 2$ & 0.950 & 0.969 & 0.980 & 0.952 & 0.952 & 12.682 & 12.926 & 14.162 & 14.512 & $(0.05,0.02,0.048)$ & $(0.05,0.02,0.048)$ \\
\hline S3 & 0.950 & 0.979 & 0.970 & 0.957 & 0.956 & 12.183 & 12.427 & 14.300 & 14.650 & $(0.05,0.03,0.044)$ & $(0.05,0.03,0.044)$ \\
\hline S4 & 0.950 & 0.990 & 0.960 & 0.965 & 0.965 & 11.808 & 12.051 & 14.626 & 14.976 & $(0.05,0.04,0.035)$ & $(0.05,0.04,0.035)$ \\
\hline S5 & 0.900 & 0.918 & 0.980 & 0.901 & 0.901 & 12.682 & 12.926 & 12.902 & 13.252 & $(0.10,0.02,0.099)$ & $(0.10,0.02,0.099)$ \\
\hline S6 & 0.900 & 0.938 & 0.960 & 0.904 & 0.904 & 11.808 & 12.051 & 12.965 & 13.315 & $(0.10,0.04,0.096)$ & $(0.10,0.04,0.096)$ \\
\hline S7 & 0.900 & 0.957 & 0.940 & 0.912 & 0.912 & 11.242 & 11.486 & 13.122 & 13.472 & $(0.10,0.06,0.088)$ & $(0.10,0.06,0.088)$ \\
\hline S8 & 0.900 & 0.978 & 0.920 & 0.929 & 0.928 & 10.811 & 11.054 & 13.483 & 13.833 & $(0.10,0.08,0.071)$ & $(0.10,0.08,0.072)$ \\
\hline S9 & 0.800 & 0.808 & 0.990 & 0.800 & 0.800 & 13.469 & 13.712 & 11.434 & 11.784 & $(0.20,0.01,0.200)$ & $(0.20,0.01,0.200)$ \\
\hline S10 & 0.800 & 0.825 & 0.970 & 0.801 & 0.801 & 12.183 & 12.427 & 11.441 & 11.791 & $(0.20,0.03,0.199)$ & $(0.20,0.03,0.199)$ \\
\hline S11 & 0.800 & 0.851 & 0.940 & 0.804 & 0.803 & 11.242 & 11.486 & 11.473 & 11.823 & $(0.20,0.06,0.196)$ & $(0.20,0.06,0.197)$ \\
\hline S12 & 0.800 & 0.879 & 0.910 & 0.810 & 0.810 & 10.625 & 10.868 & 11.548 & 11.898 & $(0.20,0.09,0.190)$ & $(0.20,0.09,0.191)$ \\
\hline S13 & 0.800 & 0.909 & 0.880 & 0.822 & 0.821 & 10.147 & 10.390 & 11.689 & 12.039 & $(0.20,0.12,0.178)$ & $(0.20,0.12,0.179)$ \\
\hline S14 & 0.800 & 0.941 & 0.850 & 0.843 & 0.841 & 9.747 & 9.990 & 11.957 & 12.307 & $(0.20,0.15,0.157)$ & $(0.20,0.15,0.159)$ \\
\hline S15 & 0.800 & 0.976 & 0.820 & 0.884 & 0.882 & 9.398 & 9.641 & 12.568 & 12.918 & $(0.20,0.18,0.116)$ & $(0.20,0.18,0.118)$ \\
\hline
\end{tabular}




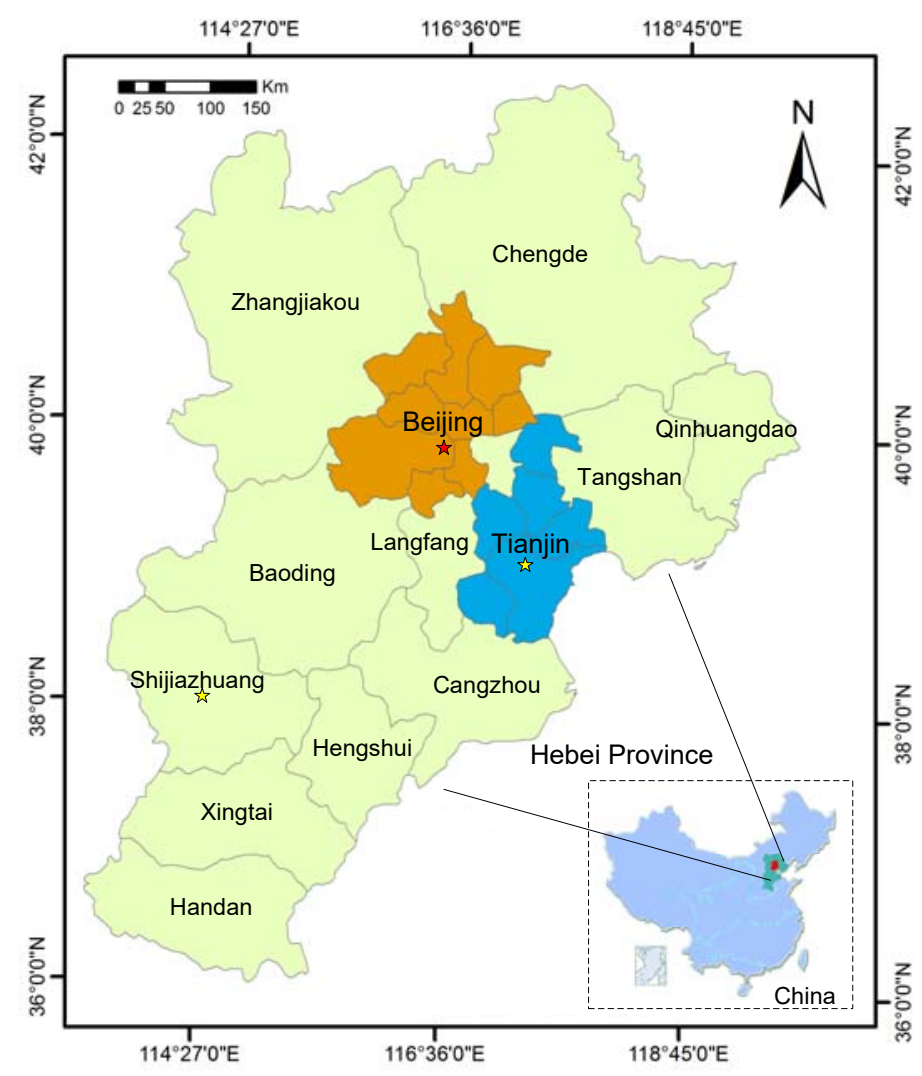

Figure 1 . The study area 


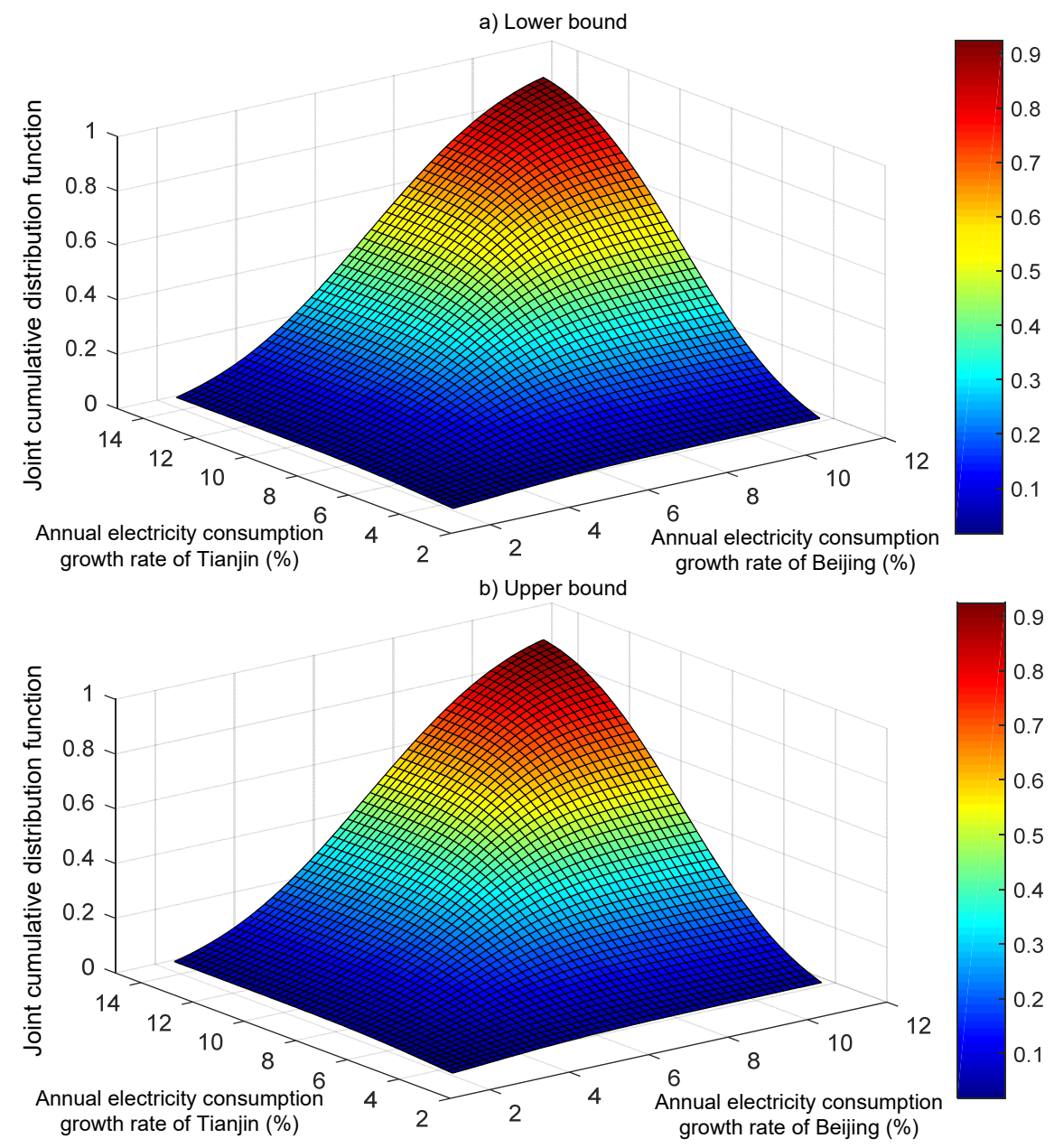

Figure 2. Joint cumulative distribution function for annual electricity consumption growth rates of Beijing and Tianjin obtained through using Gumbel-Hougaard Copula 


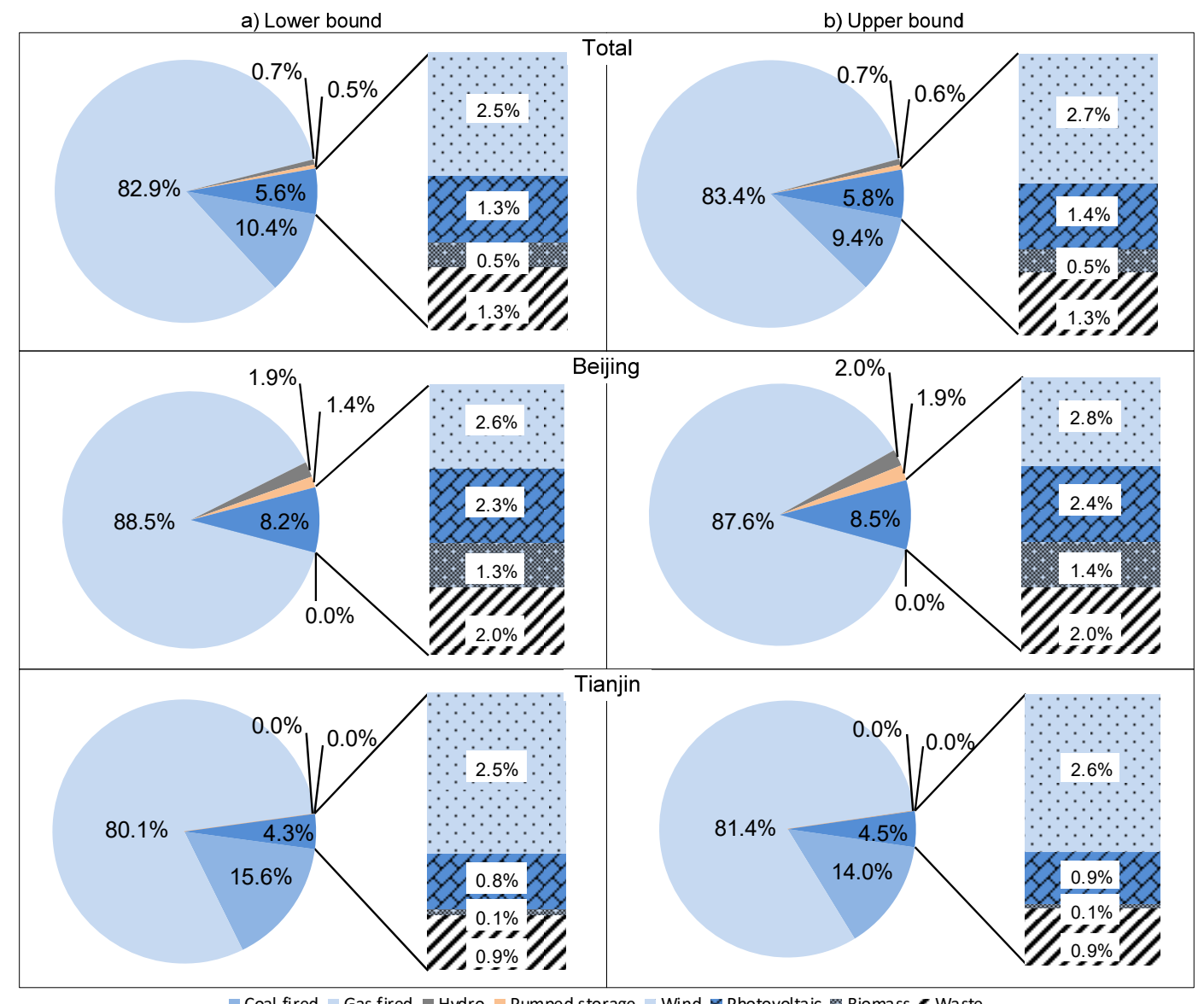

Figure 3. Electricity supply pattern 


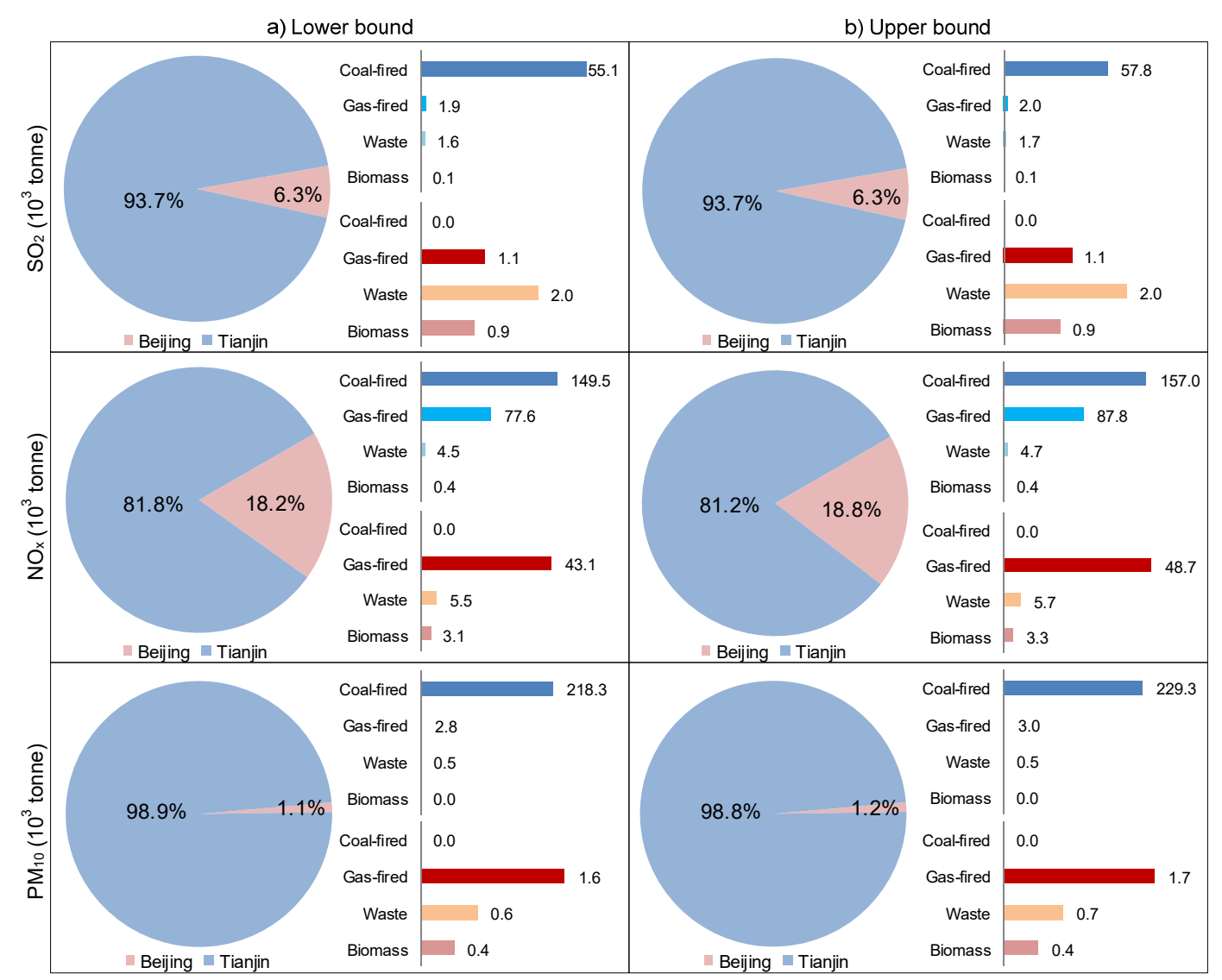

Figure 4. Pollutant emissions under different emitters 

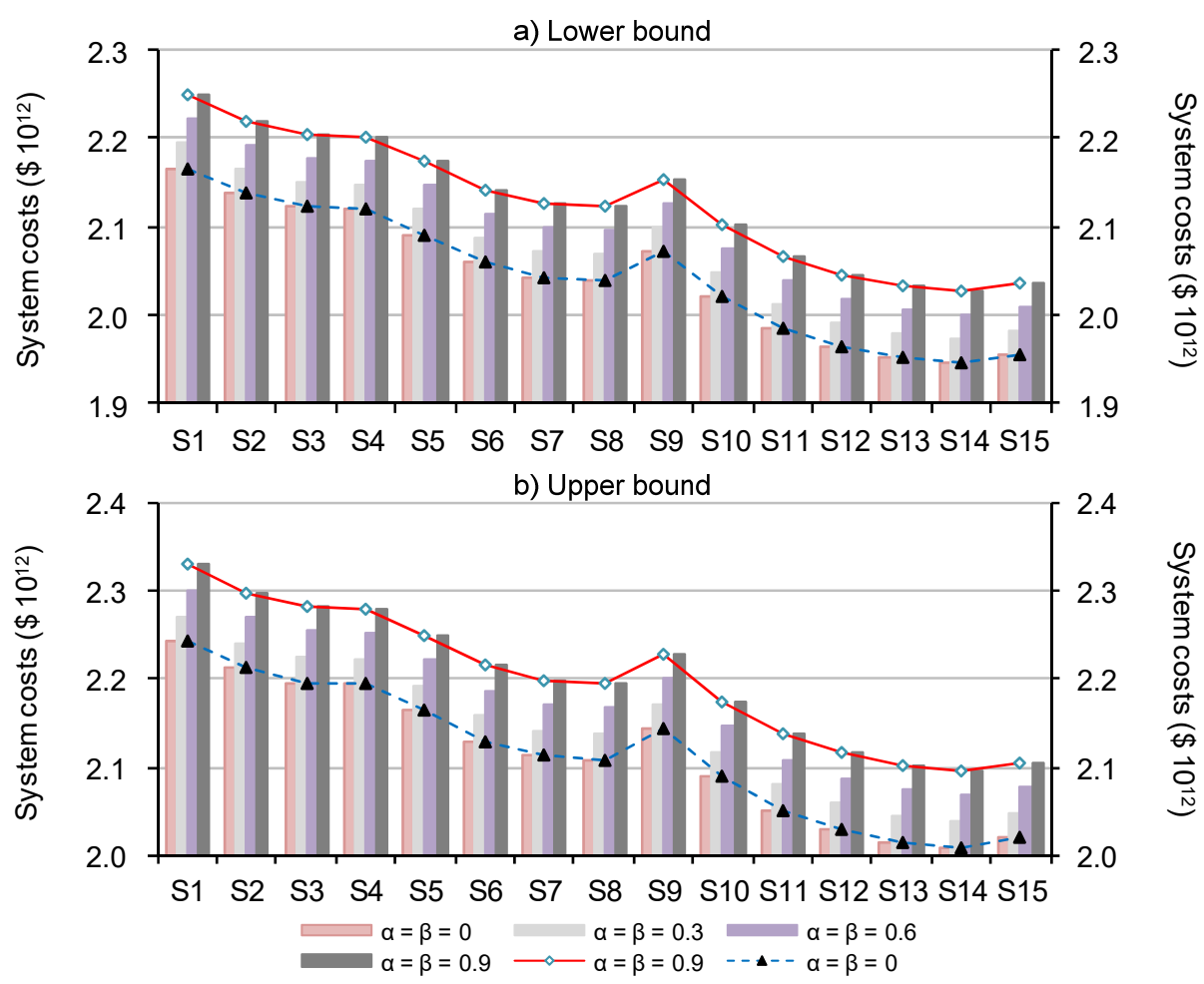

Figure 5. System costs under different scenarios 


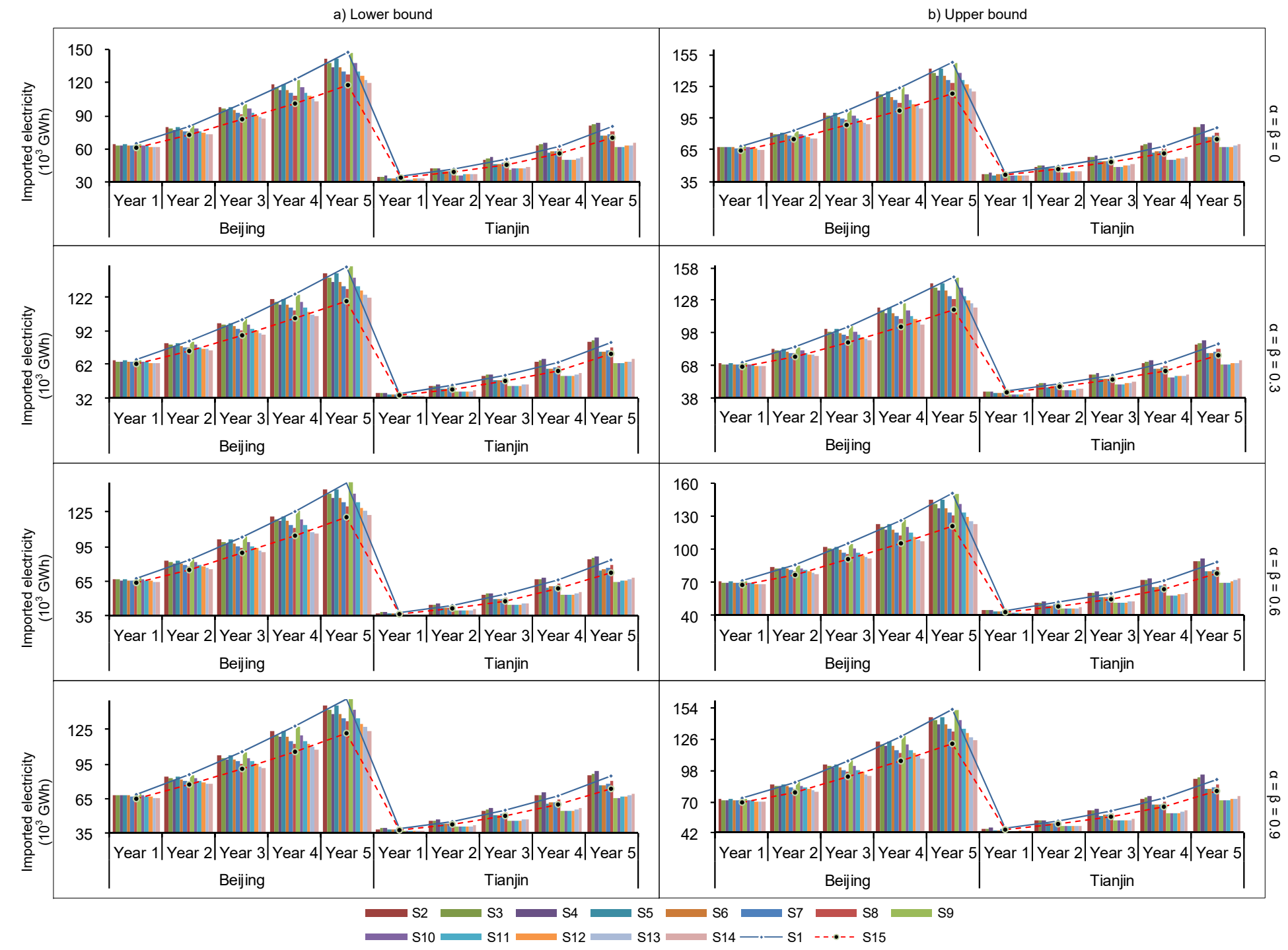

Figure 6. Imported electricity under different scenarios 

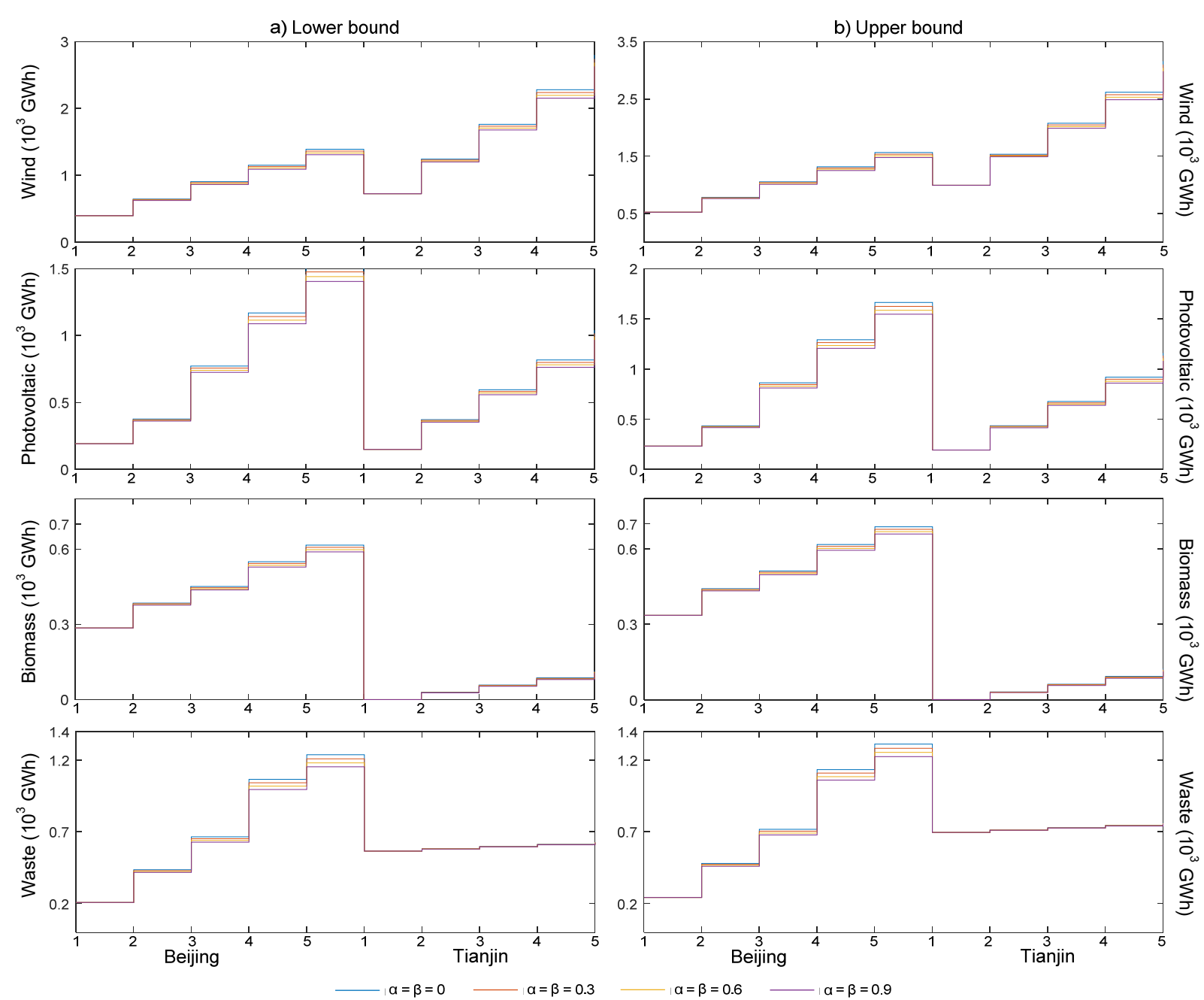

Figure 7. Electricity generated by renewable energies under different $\alpha$ and $\beta$ levels 

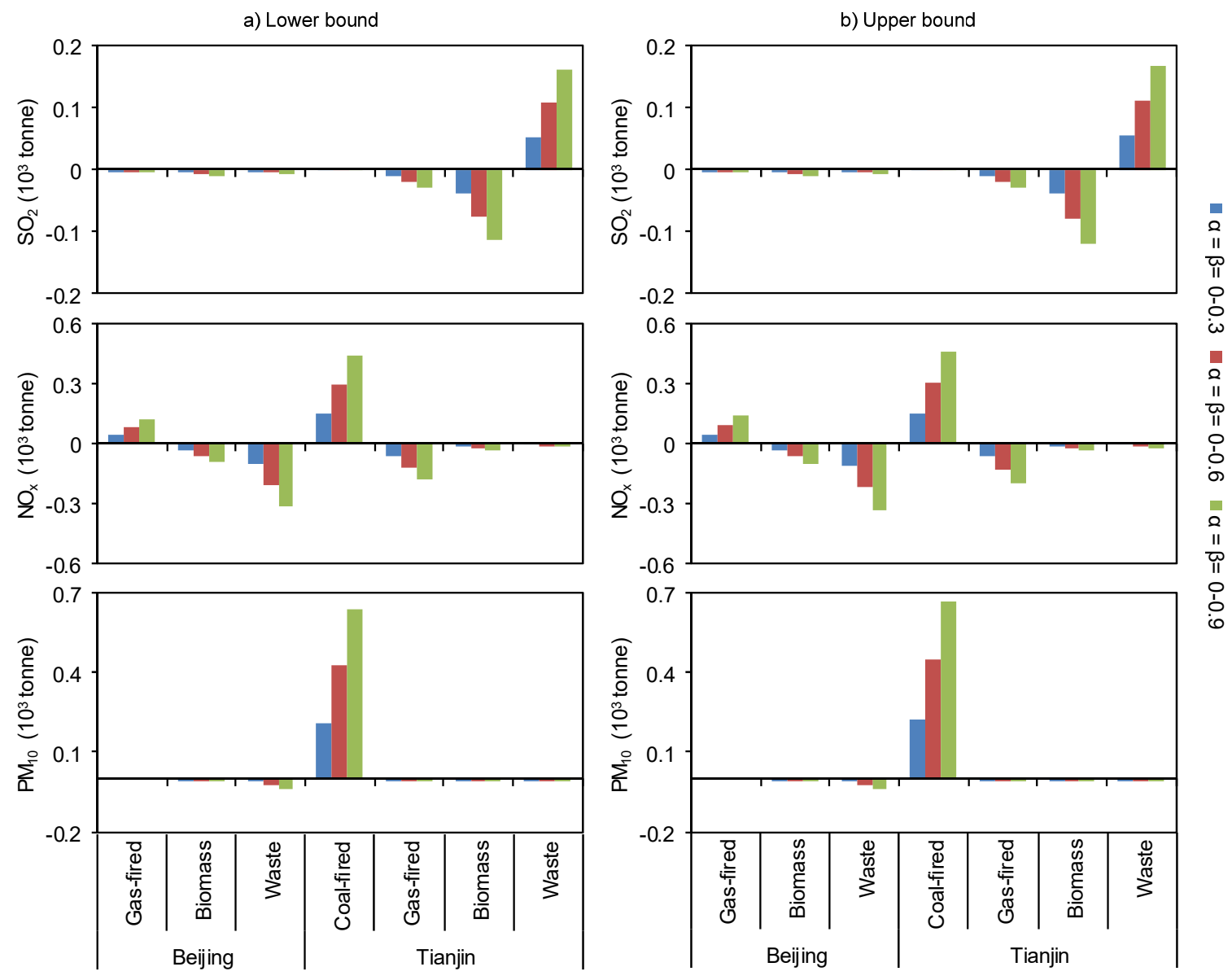

Figure 8. Pollutant emissions under different $\alpha$ and $\beta$ levels 

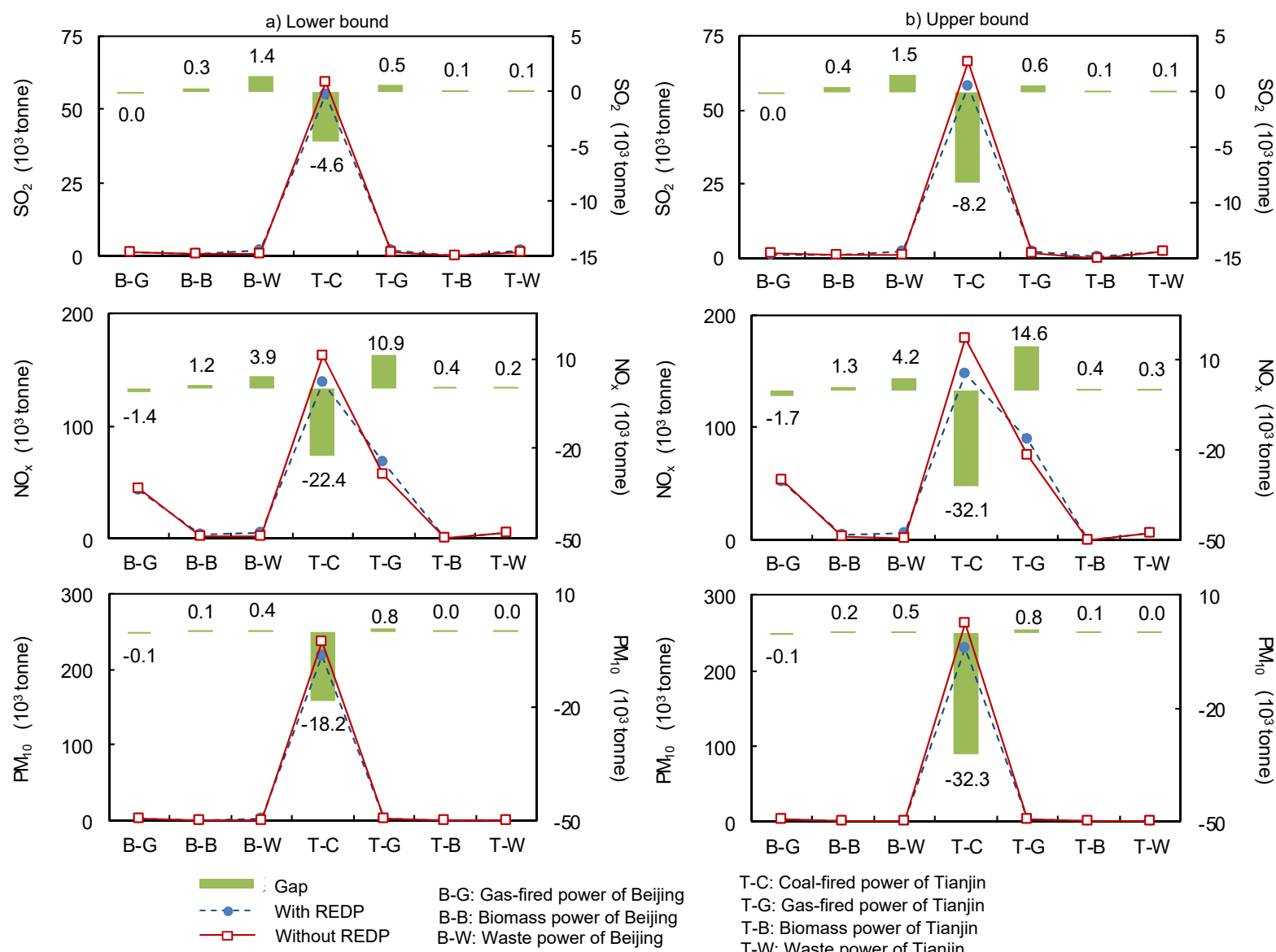

T-C: Coal-fired power of Tianjin

T-G: Gas-fired power of Tianjin

T-B: Biomass power of Tianjin

T-W: Waste power of Tianjin

Figure 9. Pollutant emissions with- and without implementing REDP 